\title{
How COVID-19 Influences the Food Supply Chain: An Empirical Investigation of Developing Countries
}

\author{
Jamal Ahmed Al-Doori ${ }^{*}$, Naser Khdour ${ }^{1}$, Eyad A. Shaban ${ }^{1}$, Tamara Mahmoud al Qaruty ${ }^{1}$ \\ ${ }^{1}$ Business Administration, Al-Ahliyya Amman University Al-Saro, Al-Salt, Amman, Jordan
}

\begin{abstract}
A supply chain is a network of organizations that due to globalization are all deeply connected. If there is a disruption to one of those organizations, it can destroy the system, which will ultimately influence the economy and especially the population. It has been found that COVID19 has negatively affected most nations around the globe. Developing countries have suffered the most due to a lack of resources. After an extensive literature review, it can be concluded that the greatest challenges were experienced in the food supply chain; industries were halted, but people needed enough food to survive. This study aimed to verify the impact of COVID-19 on the economy and food supply chain of Iraq. Six hypotheses were developed and data were collected from the Iraqi food supply chain. The data were cleaned and then analyzed through SmartPLS. It was found that COVID-19 has caused a high rate of inflation and decreased the human development index rate. Although several countries have lowered their interest rate, the advantages of this have failed to reach ordinary people. This study will help the government and managers in the food supply chain industry in their decision-making processes. The study will also support researchers in developing new theories in this regard.
\end{abstract}

Keywords: COVID-19; Food industry; Supply chain

\section{Introduction}

The study tests the performance of aid companies in Iraq through task-technology fit, examining the impact of information system compatibility, information technology, and new technologies on performance. Research supports the idea that more procurement processes should be considered (Al-Doori, 2018). To get the best return on investment, managers should focus on devoting resources to information technology to enhance performance. How can a company improve its overall performance? The use of raw or new materials will become less important. Appropriate technologies reduce carbon emissions, helping to stabilize the environment (Hapsari et al., 2019). This new space occupied by organizations will create new investments and job opportunities as more skilled people are hired to benefit from their expertise (Shahbaz et al., 2020a). This research helps to create awareness among the supply chain of metalworking companies and motivates them to turn their traditional supply chains into functional ones. Information on reuse and supply chains has already been created, but now is the time to take action (Areiqat and Al-Doori, 2018).

Internal lean practices eliminate the waste of money and time within the supply chain system (Goransson, 2019). The term "lean" pertains to a system that uses less input to 
supply at a mass-production speed and at regular intervals, ultimately providing additional benefits (or value added) (Silpcharu and Thaisom, 2020). Supply chain managers have a better understanding of chain management needs and, therefore, can support the strategic decision-making process to help firms remain competitive in the market place (Al-Doori et al., 2020). Open sharing of knowledge regarding inventory levels, forecasts, marketing, and selling techniques can reduce the uncertainty between stakeholders and result in improved performance (Bai, 2011).

In this section, past research is mentioned to identify a theoretical framework and potential hypotheses for this study (Aung and Chang, 2014).

\subsection{Food Supply Chain}

The sector has created job opportunities in the domestic market (World Food Programme, 2020). According to the Iraq Food Industries Union, the most important food processing industries in the West Bank are related to the agricultural products targeted for this purpose: canned vegetables and fruits (Gunasekaran et al., 2001; Shahbaz et al., 2020b). In Iraq, there are only a few industries that specialize in producing canned vegetables and fruits, and they currently employ hundreds of workers. Investment in this industry is estimated to be in the millions. These products make up around $20 \%$ of the total market capitalization and around 30\% of the market (Singh, 2018), and make a major contribution to total exports (Akhtar, 2013).

\subsection{Economic Conditions During COVID-19}

The food industry has been operating for centuries. It has recently grown rapidly and is now considered an essential factor of economic growth in many countries (United Nations Development Programme, 2016). It is noted that China currently leads in exports (Amuda, 2020). In Iraq, the food supply chain is highly ranked around the world in terms of foreign exchange (Shahbaz et al., 2020c). The present study focuses on those factors to assess the effect of economic indicators on commercial performance within the food industries of developing countries (European Environment Agency, 2019). Therefore, the purpose of the present study is to examine the role of economic indicators in the performance of selling goods (Al-Doori, 2020). Studies have revealed that economic indicators have a significant effect in developing countries (World Bank Group, 2017).

\subsection{COVID-19 Impact on Economy}

It has been found that 426,000 food organizations were badly impacted due to a sudden halt of operations during the COVID-19 outbreak (Hakimah et al., 2019). Most of these organizations indirectly impact the inflation rate and human development as they are directly linked to a basic need of humanity (Nikou and Selamat, 2013). Most registered beneficiaries (99 percent) in developing countries work with national institutions to enhance the capacity of the economy and assist the poor and vulnerable through social safety nets following the job losses linked to COVID-19-related closures (Zusmelia et al., 2020).

\subsection{Research Framework and Hypotheses}

After an extensive literature review, it has been found that COVID-19 has caused a high inflation rate, a high interest rate, and a decrease in the human development index (HDI) rate. This has had a drastic negative impact on the Iraqi economy and specifically on the food supply chain. Thus, the below framework has been adopted and needs to be verified empirically. 


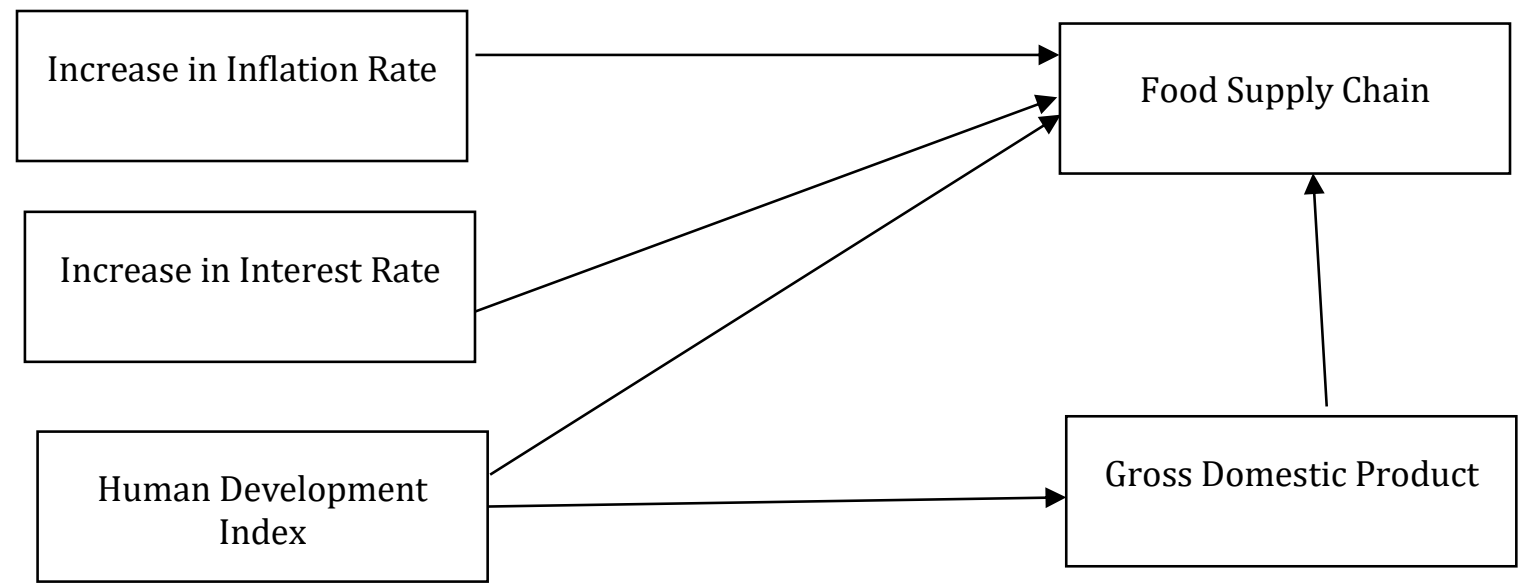

Figure 1 Research Framework

Inflation has a significant relationship with the acquisition of products and services. The food supply chain supports the transfer of products and services; therefore, it has a significant impact on inflation. Inflation raises prices, which negatively affects purchasing power (United Nations Development Programme, 2016). A model of the underlying assets is shown in Figure 1 and is proposed by the hypotheses (Olson and Wu, 2011). A country usually has a better HDI when education indicators have higher values, which also results in a higher gross domestic product (GDP) per capita (Hakimah et al., 2019). However, political influence can interfere with money matters (Goransson, 2019). Therefore, it is to the customer's advantage to permit the installment from the supplier to expire (Singh, 2018).

The HDI is one of the integrated indicators, alongside individual income, life expectancy and education, of the four stages of human development (United Nations Development Programme, 2016). HDI is one of the key development indicators, with a robust relationship to GDP and procurement performance in various firms (World Food Programme, 2020). Therefore, the hypotheses below are proposed (Koroleva et al., 2020).

H1: An increasing inflation rate negatively affects the food supply chain of Iraq

H2: An increasing interest rate negatively affects the food supply chain of Iraq

H3: An increasing HDI positively affects the food supply chain of Iraq

H4: An increasing HDI positively affects the GDP of Iraq

H5: An increasing GDP positively affects the food supply chain of Iraq

H6: GDP mediates the relationship between HDI and the supply chain of Iraq

\section{Research Methodology}

This study generalizes the findings based on a sample of data, so the research philosophy is positivism. In this quantitative study, the researcher performed descriptive statistics and analyzed company information and quantity variables associated framework using the Social Sciences Scientific Package (SPSS).

The relationships between independent and dependent variables are expressed through uploads that inform researchers about the level of a given indicator that can measure variables. In addition, the confirmatory analysis in the SPSS is prepared and validated by the rating model.

In this research project, a pilot test was performed prior to the actual research. Pilot testing serves as a tool to help the researcher identify problems and make necessary 
adjustments. Key data were collected through a questionnaire and then processed via SPSS. Final data analysis was done using structural equation modeling through SmartPLS.

\section{Results and Discussion}

As stated in the methodology session, SPSS was used for descriptive analysis, the measurement model, and the structural model. Before the final data analysis, all the data were cleaned and manually screened through various methods for missing values. Outliers were identified through SPSS. There was no major flaw in the data. After making all necessary changes, the data were ready for analysis. Table 1 describes the reliability of data. All the values are within the acceptable limits. Thus, it can be concluded that the data are reliable for structural analysis.

Table 1 Reliability analysis

\begin{tabular}{cccc}
\hline & Cronbach's Alpha & Composite Reliability & $\begin{array}{c}\text { Average Variance } \\
\text { Extracted }\end{array}$ \\
\hline FSC & 0.862 & 0.684 & 0.626 \\
GDP & 0.835 & 0.775 & 0.504 \\
HDI & 0.867 & 0.698 & 0.595 \\
INF & 0.822 & 0.868 & 0.524 \\
INT & 0.816 & 0.861 & 0.558 \\
\hline
\end{tabular}

Note: $\mathrm{FSC}=$ food supply chain; INF = inflation; INT = interest rate

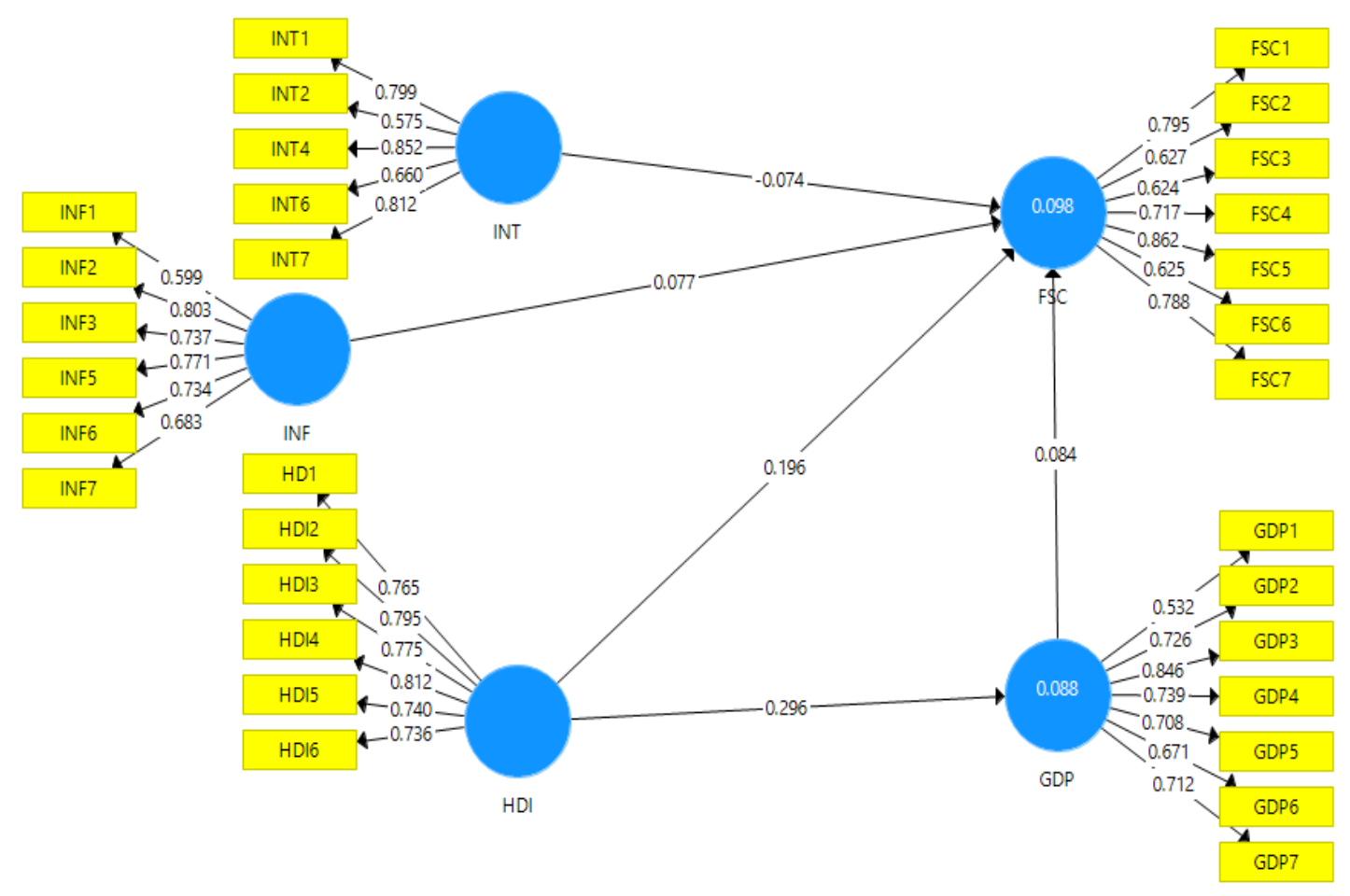

Figure 2 Measurement model

This study checked the reliability and validity of the data. Tables 1,2 , and 3 show that all the values meet the threshold limits. Thus, it can be concluded that the instrument is valid and reliable (Farissi et al., 2021). The mean values ranged from 3.2114 to 3.7543, which shows that the responses to the questionnaire tended to be more neutral and in 
agreement. The standard deviation values show the deviation of responses from the means, ranging from .74135 to 1.02596 (Prakash et al., 2017). This indicates that respondents had differing opinions regarding the questions used in the survey tool.

Table 2 Hypotheses testing

\begin{tabular}{ccccc}
\hline Hypothesis & Relationships & Beta Values & T Values & Decisions \\
\hline H1 & INT $\rightarrow$ FSC & 0.084 & 1.286 & Accepted \\
H2 & INF $\rightarrow$ FSC & 0.097 & 2.478 & Accepted \\
H3 & HDI $\rightarrow$ FSC & 0.606 & 4.333 & Accepted \\
H4 & HDI $\rightarrow$ GDP & 0.660 & 3.135 & Accepted \\
H5 & GDP $\rightarrow$ FSC & 0.004 & 0.784 & Rejected \\
\hline
\end{tabular}

Table 3 Mediation analysis

\begin{tabular}{ccccc}
\hline Hypothesis & Relationship & Beta Value & T Value & Result \\
\hline H6 & HDI -> GDP -> FSC & 0.019 & 0.786 & Rejected \\
\hline
\end{tabular}

The contribution of this research project is summarized below. The findings will be useful for regulatory authorities and researchers of the Iraqi food supply chain, and readers of this project (Shahbaz et al., 2019b). The specific contribution of this research to the related literature concerns the impact of supply chain practices on the economy in the Iraqi food supply chain industry. This study also investigated the fact that leadership, supplier role, lean practices, quality information analysis, and customer focus promote organizational innovation. The main supply chain factors discovered in this research are the interest rate and inflation rate (Al-Doori et al., 2019). The performance of food supply chain organizations is impacted by these factors, which ultimately affects the economy of the developing countries (Shahbaz et al., 2019a). This research is based on the food industry only; future studies can be conducted on other industries. Future researchers may widen their scope and consider all industries in their sample to have a better understanding of the impact on supply chain performance.

\section{Conclusions}

It can be concluded that although various countries have taken innovative measures to handle the COVID-19 pandemic, developing countries were not prepared for such a gigantic incident. Developed countries had enough resources to manage the unusual situation, but developing countries, with their scarce resources, were highly dependent on support from developed countries. Nonetheless, developed countries also suffered as it was found that COVID-19 negatively affected the inflation rate and human development index rate, which ultimately hamstrung economies and food supply chains. This study recommends that decision-makers involve all stakeholders in decision making. This will only be possible when there is enough information flow through the internet. Future studies can be conducted based on theory and suggest more mitigation strategies. 


\section{References}

Akhtar, P., 2013. Determinants of Coordination Effectiveness of Selected International AgriFood Supply Chains: A Structural Equation Modelling Approach. Master's Thesis, Graduate Program, Massey University, Palmerston North, New Zealand

Al-Doori, J.A., 2018. The Impact of Supply Chain Management Approaches on Supply Chain Performance in Iraq. International Journal of Supply Chain Management, Volume 7(5), pp. $13-21$

Al-Doori, J.A., 2020. The Impact of Lean Practices on Operational Performance in the Banking Sector: An Empirical Investigation. International Journal of Services and Operations Management, Volume 37(1), pp. 27-39

Al-Doori, J.A., Aldabbagh, I., Mohammad, M.M., Qawasmeh, R., 2020. The Impact of Islamic Work Ethics on Job Performance with Mediating Role of Intrinsic Motivation. Academy of Strategic Management Journal, Volume 19(2), pp. 1-11

Al-Doori, J.A., Alhorani, A., Areiqat, A.Y., 2019. The Role of Just in Time, Total Quality Management, and Supply Chain Management toward Better Operational Performance. The Journal of Social Sciences Research, Volume 5(4), pp. 949-956

Amuda, Y.J., 2020. Impact of Coronavirus on Small and Medium Enterprises (SMEs): Towards Post-Covid-19 Economic Recovery in Nigeria. Academy of Strategic Management Journal, Volume 19(6), pp. 1-11

Areiqat, A.Y., Al-Doori, J.A., 2018. The Role of Electronic Training in Employee Performance Development. International Journal of Advances in Agriculture Sciences, Volume 7(6), pp. $10-15$

Aung, M.M., Chang, Y.S., 2014. Traceability in a Food Supply Chain: Safety and Quality Perspectives. Food Control, Volume 39, pp. 172-184

Bai, L., 2011. Exploratory Study of Environmentally Sustainable Supply Chain in New Zealand Food Industry. Master's Thesis, Graduate Program, Massey University, Palmerston North, New Zealand

European Environment Agency, 2019. Economy and Development, Volume 53 Issue 9

Farissi, A., El Oumami, M., Beidouri, Z., 2021. Assessing Lean Adoption in Food Companies: The Case of Morocco. International Journal of Technology, Volume 12(1), pp. 5-14

Goransson, M., 2019. Dynamically Predicted Shelf-life Service: Exploring and Evaluating a Potential Sustainable Food Supply Chain Innovation. Master's Thesis, Graduate Program, Lund University, Lund, Sweden

Gunasekaran, A., Patel, C., Tirtiroglu, E., 2001. Performance Measures and Metrics in a Supply Chain Environment. International Journal of Operations \& Production Management, Volume 21(1/2), pp. 71-87

Hakimah, Y., Hildayanti, S.K., Nugraha, A.T., 2019. Influence of Economic Indicators on Supply Chain: Evidence from Indonesian Fishing Industry. International Journal of Supply Chain Management, Volume 8(5), pp. 854-863

Hapsari, K.L., Tharifa, F., Moersidik, S.S., Adityosulindro, S., Priadi, C.R., 2019. The Effect of Magnesium Sulfate Addition on Volatile Solid Destruction and Chemical Oxygen Demand Reduction of Food Waste Anaerobic Digestion. International Journal of Technology, Volume 10(8), pp. 1602-1608

Koroleva, E., Baggieri, M., Nalwanga, S., 2020. Company Performance: Are Environmental, Social, and Governance Factors Important? International Journal of Technology. Volume 11(8), pp. 1468-1477

Nikou, S., Selamat, H., 2013. Risk Management Capability within Malaysian Food Supply Chains. International Journal of Agriculture and Economic Development, Volume 1(1), pp. 37-54 
Olson, D.L., Wu, D., 2011. Risk Management Models for Supply Chain: A Scenario Analysis of Outsourcing to China. Supply Chain Management: An International Journal, Volume 16(6), pp. 401-408

Prakash, S., Soni, G., Rathore, A.P.S., Singh, S., 2017. Risk Analysis and Mitigation for Perishable Food Supply Chain: A Case of Dairy Industry. Benchmarking: An International Journal, Volume 24(1), pp. 2-23

Shahbaz, M.S., Mubarik, M.S., Mubarak, M.F., Irshad, M.B., 2019a. The Impact of Lean Practices on Educational Performance: An Empirical Investigation for Public Sector Universities of Malaysia. Journal of Independent Studies and Research-Management, Social Sciences and Economics, Volume 17(2), pp. 85-96

Shahbaz, M.S., Othman, B.A., Salman, P.M., Memon, D.A., Rasi, R.Z.B.R., 2020a. A Proposed Conceptual Action Plan for Identification, Assessment and Mitigation of Supply Chain Risks. International Journal of Advanced Operations Management, Volume 12(1), pp. 65-80

Shahbaz, M.S., Qureshi, M.A., Sohu, S., Keerio, M.A., 2020b. The Impacts of Operational Risks in the Supply Chain of Construction Projects in Malaysia. Tehnicki Vjesnik, Volume 27(6), pp. 1887-1893

Shahbaz, M.S., Shaikh, F.A., Qureshi, M.A., Jamali, Q.B., Sohu, S., 2019b. The Influence of Supply Chain Collaboration on Supply Chain Performance for Malaysian Manufacturing Industry. Journal of Organizational Behavior Research, Volume 4(2), pp. 203-218

Shahbaz, M.S., Soomro, A.B., Soomro, S., Sohu, S., Ahmed, B., 2020c. The Role of Supply Chain Relationships in Risk Management by Enhancing Customer Satisfaction. International Journal of Disaster Recovery and Business Continuity, Volume 11(1), pp. 1756-1765

Silpcharu, T., Thaisom, R., 2020. Guidelines in Applying Sufficiency Economy Philosophy to Enhance Sustainable Success in Business. Academy of Strategic Management Journal, Volume 19(6), pp. 1-6

Singh, A., 2018. Improving Efficiency and Reducing Waste for Sustainable Beef Supply Chain. Dissertation for Degree of Doctor of Philosophy, Graduate Program, Norwich Business School, University of East Anglia, United Kingdom

United Nations Development Programme, 2016. Human Development Report 2016, New York

World Bank Group, 2017. Prospects for Growth and Jobs in the Palestinian Economy: A General Equilibrium Analysis. Public Disclosure Authorized, Washington, DC

World Food Programme, 2020. WFP Palestine Country Brief: August 2020

Zusmelia, Ansofino, Noer, M., Iswandi, Momon, Dahen, L.D., Rosya, N.D., 2020. Strategies to Manage Regional Development Inequality for Economic Recovery During the Covid-19 Period. Academy of Strategic Management Journal, Volume 19(1), pp. 1-28 